form and to suppress or ignore small deviations from symmetry.

Twenty years ago a flurry of papers in prestigious journals announced that, when cells in tissue culture divide, the shapes and migration tracks of the daughters display parallel or mirror symmetries. These reports were fascinating because they raised the possibility of an intrinsic pre-programming of cell shape and migration. But unfortunately they were also wrong. Later analysis showed that the same degree of symmetry was claimed by observers looking at tracks on a computer screen - even when these were generated by a completely random process. It would be interesting to see a similarly rigorous analysis of some of the patterns reported in this book. The fearful tiger's face may not be as symmetrical as we suppose, and the much-vaunted Fibonacci series of leaves and petals may in fact be quite difficult to find in the average weed patch. I am not saying that regularities do not exist - just that these rules are not obeyed with great precision. Can they be that important to the organism?

Living organisms occupy space and time, and possess volume and mass. They are subject to the same laws of physics and chemistry as snowflakes, salt crystals and other physical objects, and like these physical objects are expected to display regularities and patterns. Indeed, the complexity of living systems, their capacity for unlimited division and tendency to homeostasis, should make them especially prone to geometrical or mathematical regularities.

But, far from being a "secret of life", these patterns are what living things have in common with the rest of the Universe. They exist by default and are immediately abrogated if there is any selective advantage to be gained - as in animal mimicry by flowers, for example.

Fascinating, intriguing, beautiful, mathematically pleasing though these patterns are, they are of limited use in understanding the machinery of life. In most cases they simply reveal the operation of some well-established physical principle, such as the close packing of spheres, or surface tension, or the diffusion of chemicals. Useful to know, but hardly a key to unlock further mysteries.

Where would we be if, back in 1917, biologists had read that the forms of dividing cells were governed by the same simple equations as soap bubbles and promptly abandoned all further interest in the matter? We'd know a lot less about the molecular basis of cell division and cell shape - although Pythagoras would have approved!

Dennis Bray is in the Department of Zoology,

University of Cambridge, Downing Street,

Cambridge CB2 3EJ, UK.

\section{Bouffi à la girafe}

\section{Zarafa: A Giraffe's True Story from Deep in Africa to the Heart of Paris} by Michael Allin

Walker: 1998. Pp. 224. \$22. To be published

in the UK by Headline in October, $£ 12.99$

\section{Philippe Janvier}

The expression "It's either that or comb the giraffe..." is still used in France to refer to a boring job one has to do. I would certainly not apply it to the task of reviewing this book, which is an admirably documented and charming account of the long journey made by the first giraffe to arrive alive in France.

From Sudan to Paris, the giraffe's progress was accompanied by considerable public interest. This was in 1827, during the reign of Charles X, who had been given the giraffe by the viceroy of Egypt, Muhammad Ali. During her long walk from Marseille to Paris, the giraffe, whom Allin calls Zarafa (the Arabic for giraffe, from a word meaning 'lovely one'), attracted crowds of people. She finally arrived safely at the Jardin des Plantes, where she lived until 1845. For several years, the giraffe was at the heart of Parisian life. Fashions were 'à la girafe' - men's cravats knotted under the chin and women's hair piled up so high that they had to sit on the floors of their carriages. Zarafa is now stuffed and resides in the natural history museum at $\mathrm{La}$ Rochelle, in western France.

Allin places Zarafa's story in the political and scientific context of the time: Napoleon's adventurous conquest - and defeat - in Egypt, the rise of Egyptology, the restoration and ultimate fall of the monarchy in France, and the intense scientific activity in the Muséum National d'Histoire Naturelle in Paris. Among the prominent characters are the French consul general in Egypt, the famous tomb robber Bernardino Drovetti, who organized Zarafa's journey to Marseille, and Etienne Geoffroy Saint-Hilaire, a renowned professor at the Muséum National d'Histoire Naturelle.

Geoffroy Saint-Hilaire started his career at the museum at the age of 21 , and in his first year there, in 1793, he was faced with the problem of accommodating in the Jardin des Plantes a number of privately owned exotic animals that a revolutionary law had 'freed from slavery'. He solved this problem by starting the first public menagerie, which at first he had to maintain with his own money. Although he was 55 and a world-famous scientist when the giraffe arrived in Marseille, Geoffroy Saint-Hilaire again took personal charge, following the precious animal step by step, for 21 days, to Paris. As those who have experienced French bureaucracy will know, this do-it-yourself attitude was certainly the best way of ensuring Zarafa's survival.

Allin should perhaps have speculated

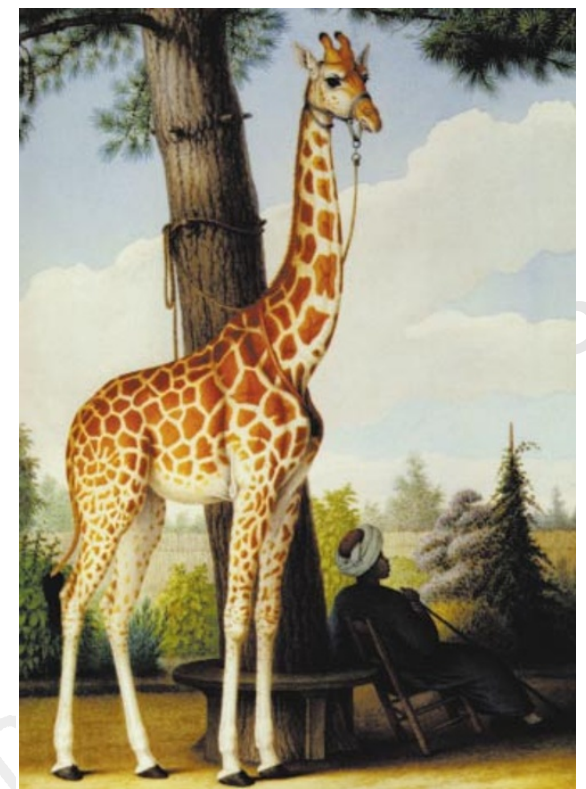

Zarafa with her lifelong Sudanese attendant, Atir - both great hits with the ladies of Paris.

about the reasons for Zarafa's fame; after all, a living giraffe that arrived in London the same year went almost unnoticed. One reason for the giraffe-mania in Paris may have been the vivid interest of the French at that time in natural history, prompted by the writings of Buffon, which remain popular to this day (see Nature 390, 37; 1997).

Moreover, the neck of the giraffe remained the symbol of Lamarck's ideas on evolution, which were dear to the heart of some learned French people, including Geoffroy Saint-Hilaire.

This charming and never boring account reads like a novel. I recommend it to historians of science and - why not? - to scientists, especially those at the top of their careers, who will learn from Geoffroy SaintHilaire how to take matters in hand.

Philippe Janvier is at the Laboratoire de

Paléontologie, Muséum National d'Histoire Naturelle, 8 Rue Buffon, 75005 Paris, France.

\section{The is and the ought}

\section{The Ethics of Science: An Introduction \\ by David B. Resnik \\ Routledge: 1998. Pp. 221. £45, \$75 (hbk);

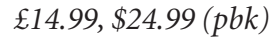

\section{Brian Martin}

Scientists know they should not fabricate data or plagiarize the work of others. But what about gift authorship for the head of the lab, making exaggerated claims about results on a grant application, or keeping results secret for reasons of commercial confidentiality? There are no ethics committees to address such topics.

Ethical issues abound in scientific work, 
but few scientists have formally studied ethics. They develop most of their responses to ethical issues by observing how specific problems are dealt with in practice, leaving no room for ethical theory.

Yet this ad hoc way of learning about ethics leaves much to be desired. What does a scientist learn when supervisors and colleagues use sloppy lab techniques, divert grant funds for undeclared purposes, appoint cronies or lovers over more talented applicants, provide hostile referee reports on competitors' papers, or fail to report some findings that might damage the sales of a profitable drug?

One way of promoting more ethical behaviour in science is to get science students to study ethical issues: David Resnik's book is an excellent text for this purpose. After an overview of ethical theory and the nature of science as a profession, it tackles many ethical issues, including those involving error, conflict of interest, allocating credit, harassment, recruitment, research on humans and animals, and secrecy.

Resnik adopts a traditional idea of science as a quest for objective knowledge, in which honesty and openness are central. His basic model is drawn from academic science, which poses some difficult dilemmas for researchers working in industrial and military settings.

He deals with secrecy in industrial and military science but not with some wider issues, such as whether it is ethical to devote enormous resources to achieve a slight improvement in sales potential or weapons efficiency when millions of people are suffering from lack of attention to basic needs. However, his framework can be used to look at such issues.

Resnik is a philosopher: his main concern is not what scientists do, but what they should do. Practising scientists may therefore be impatient with his analysis, which makes few concessions to the practicalities of surviving and succeeding as a researcher in a climate in which misrepresentation, bias and exploitation are commonplace.

How many scientists, after all, can afford to be entirely truthful about all their findings (including mistakes), share all their data, never give an undeserved citation (for example, to a supervisor or possible referee), support all whistleblowers and avoid any conflict of interests due to funding? Resnik's book perhaps needs to be supplemented by a practical manual on how to survive as an ethical scientist.

He provides a very balanced treatment of the issues, but is sometimes so careful as to be rather dry - despite the spice of topics such as the Baltimore affair and cold fusion. One limitation, though, is that most of the examples and references he cites come from the United States.

David Resnik is right to say that change will not occur until more scientists behave ethically, and that raising ethical issues with students is a good place to start. Saving the best for last, the book's appendix contains 50 case studies that should provoke many stimulating discussions.

Brian Martin is in Science and Technology Studies, University of Wollongong, NSW 2522, Australia.

\section{TheFAQs of astronomy}

\section{Just Visiting This Planet: Merlin Answers More Questions about Everything under the Sun, Moon, and Stars}

by Neil de Grasse Tyson

Doubleday: 1998. Pp. $336 . \$ 12.95$ (pbk)

\section{The Astronomy Cafe: 365 Questions} and Answers from "Ask the

\section{Astronomer"}

by Sten Odenwald

W. H. Freeman: 1998. Pp. 252. \$14.95,

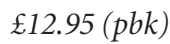

\section{Jay M. Pasachoff}

From the planet Omniscia, Neil de Grasse Tyson's modern-day Merlin answers questions from all comers, or at least from those who subscribe to Star Date, a magazine produced by the McDonald Observatory of the University of Texas.

Tyson, a Princeton astrophysicist who also directs the Hayden Planetarium of the American Museum of Natural History in New York, has developed his Merlin persona over the past 15 years. As he supervises the construction of the new planetarium in New York, the old one having met the wrecker's ball, his influence in teaching astronomy to the general public, including children, is as great as anyone's in the United States.

Merlin's answers are short, accurate, sometimes cute and a bit arch. Most of them are straightforward. "Dear Merlin, Couldn't the fragments of comet Shoemaker-Levy 9, when they exploded on the surface of Jupiter back in 1994, cause the massive planet to move?" is answered by "An elephant is a massive animal. Jupiter is a massive planet. A gnat that flew full speed ahead and slammed broadside into an elephant would be about one million times more effective at shoving the elephant than comet Shoemaker-Levy 9 was at shoving Jupiter."

Merlin, who tells us that he has come from the Andromeda galaxy, sometimes takes us to meet an old friend of his, such as Edwin Hubble. "Merlin: Ed, what should curious people know about your recent work? Hubble: I used the excellent hundred-inch Mount Wilson reflecting telescope here to measure the distances to 18 [galaxies]...."

Merlin serves a variety of useful purposes. Sometimes he debunks pseudoscience; he allows his friend Daniel Fahrenheit to explain his temperature scale (some four dozen such friends are described); and he tells us that the total solar eclipse of 11 August 1999 will be visible from Europe.

It is a pleasure to be able to find answers, from such an authoritative source, to what computer people now call FAQs (frequently asked questions). I had only a few quibbles with Merlin's answers. His explanation of the green flash which is sometimes visible at sunset is incomplete. And he makes the common mistake of referring to the site of the Palomar Observatory as Mount Palomar, instead of Palomar Mountain; there is no Mount Palomar.

Merlin is a good companion for students of any age - from 8 to 80 , as the circus used to put it. His earlier book, Merlin's Tour of the Universe (Columbia University Press, 1997), has still more questions and answers.

Sten Odenwald, an astronomer specializing in infrared observations, takes questions from all comers at his website, the Astronomy Cafe (www2.ari.net/home/odenwald/ cafe.html). Thousands of people have used the site's "Ask the Astronomer" feature; in the book, Odenwald provides answers to 365 of the questions. His answers are clear and accurate, and less flippant in tone than Merlin's; young children apparently do not visit the Astronomy Cafe. It is a wonderful site for non-specialists, and I am glad that the US space agency NASA has helped to support it for a while.

I even learned a few things from Odenwald's book, notably that I have substantially less than five billion years of life on Earth to look forward to. Odenwald explains how expected changes in the Sun's output may lead to the extinction of life here in only 300 million years or so.

Odenwald's book has a few diagrams scattered throughout, and a central eightpage colour section with a nice assortment of pictures. But two typographical errors in the captions are two too many.

Most of Odenwald's answers deal with topics in astronomical science. But one chapter gives answers to practical questions, such as where to get ideas for science-fair projects, or information about a particular artificial satellite. The penultimate chapter has more philosophical replies to questions such as what astronomy will be like in the twenty-first century. The final chapter is about careers in astronomy, and can be recommended to any high-school student. "What is your favourite part of astronomy?", someone asks Odenwald. He replies: "The thrill of the hunt."

We are lucky to have two such interesting books for people to dabble in. Order a dozen of each for birthdays and holidays. Jay M. Pasachoff is at the Hopkins Observatory, Williams College, 33 Lab Campus Drive, Williamstown, Massachusetts 01267, USA. 